\title{
25
}

\section{Mobilising Public Expertise in Health Research Regulation}

\author{
Michael M. Burgess
}

\subsection{INTRODUCTION}

This chapter will develop the role that deliberative public engagement should have in health research regulation. The goal of public deliberation is to mobilise the expertise that members of the public have, to explore their values in relation to specific trade-offs, with the objective of recommendations that respect diverse interests. Public deliberation requires that a small group is invited to a structured event that supports informed, civic-minded consideration of diverse perspectives on public interest. Ensuring that the perspectives considered are inclusive of perspectives that might otherwise be marginalised or silenced requires explicitly designing the small group in relation to the topic. Incorporating public expertise enhances the trustworthiness of policies and governance by explicitly acknowledging and negotiating diverse public interests. Trustworthiness is distinct from trust, so the chapter begins by exploring that distinction in the context of the example of care.data and the loss of trust in the English National Health Service's (NHS) use of electronic health records for research. While better public engagement prior to the announcement might have avoided the loss of trust, subsequent deliberative public engagement may build trustworthiness into the governance of health research endeavours and contribute to re-establishing trust.

\subsection{TRUSTWORTHINESS OF RESEARCH GOVERNANCE}

Some activities pull at the loose threads of social trust. These events threaten to undermine the presumption of legitimacy that underlie activities directed to public interest. The English NHS care.data programme is one cautionary tale (NHS, 2013). ${ }^{1}$ The trigger event was the distribution of a pamphlet to households. The pamphlet informed the public that a national database of patients' medical records would be used for patient care, to monitor outcomes, and that research would take place on anonymous datasets. The announcement was entirely legitimate within the existing regulatory regime. The Editor-in-Chief of the British Medical Journal summarises, 'But all did not go to plan. NHS England's care.data programme failed to win the public's trust and lost the battle for doctors' support. Two reports have now condemned the scheme, and last week the government decided to scrap it.' ${ }^{2}$

\footnotetext{
${ }^{1}$ NHS, 'News: NHS England sets out the next steps of public awareness about care.data', (NHS, 2013), www.england .nhs.uk/2013/10/care-data/.

F. Godlee, 'What Can We Salvage From care.data?', (2016) BMJ, 354(i3907).
} 
The stimulation of public distrust is often characterised by a political deployment of a segment of the public, but it may lead to a wider rejection of previously non-controversial trade-offs. In the case of care.data, the first response was to ensure better education about benefits and enhanced informed consent. The Caldicott Report on the care.data programme called for better technology standards, publication of disclosure procedures, an easy opt-out procedure and a 'dynamic consent' process. ${ }^{3}$

There are good reasons to doubt that improved regulation and informed consent procedures alone will restore the loss, or sustain current levels, of public trust. It was unlikely that the negative reaction to care.data had to do with an assessment of the adequacy of the regulations for privacy and access to health data. Moreover, everything proposed under care.data was perfectly lawful. It is far more likely that the reaction had to do with a rejection of what was presented as a clear case of justified use of patients' medical records. The perception was that the trade-offs were not legitimate, at least to some of the public and practitioners. The destabilisation of trust that patient information was being used in appropriate ways, even with what should have been an innocuous articulation of practice, suggests a shift in how the balance between access to information and privacy are perceived. Regulatory experts on privacy and informed consent may strengthen protection or recalibrate what is protected. But such measures do not develop an understanding and response to how a wider public might assign proportionate weight to privacy and access in issues related to research regulation. Social controversy about the relative weight of important public interests demonstrates the loss of legitimacy of previous decisions and processes. It is the legitimacy of the programmes that require public input.

The literature on public understanding of science also suggests that merely providing more detailed information and technical protections is unlikely to increase public trust. ${ }^{4}$ Although alternative models of informed consent are beyond the scope of this chapter, it seems more likely that informed consent depends on relationships of trust, and that trust, or its absence, is more of a heuristic approach that serves as a context in which people make decisions under conditions of limited time and understanding. ${ }^{5}$ Trust is often extended without assessment of whether the conditions justify trust, or are trustworthy. It also follows that trust may not be extended even when the conditions seem to merit trust. The complicated relationship between trust and trustworthiness has been discussed in another chapter (see Chuong and O'Doherty, Chapter 12) and in the introduction to this volume, citing Onora O'Neill, who encourages us to focus on demonstrating trustworthiness in order to earn trust.

The care.data experience illustrates how careful regulation within the scope of law and current research ethics, and communicating those results to a wide public, was not sufficient for the plan to be perceived as legitimate and to be trusted. Regulation of health research needs to be trustworthy, yet distrust can be stimulated despite considerable efforts and on-going vigilance. If neither trust nor distrust are based on the soundness of regulation of health research, then the sources of distrust need to be explicitly addressed.

3 F. Caldicott et al., 'Information: To Share Or Not to Share? The Information Governance Review', (UK Government Publishing Service, 2013).

4 A. Irwin and B. Wynne, Misunderstanding Science. The Public Reconstruction of Science and Technology (Abingdon: Routledge, 1996); S. Locke, 'The Public Understanding of Science - A Rhetorical Invention', (2002) Science Technology \& Human Values, 27(1), 87-111.

5 K. C. O’Doherty and M. M. Burgess, 'Developing Psychologically Compelling Understanding of the Involvement of Humans in Research', (2019) Human Arenas 2(6), 1-18. 


\subsection{PATIENTS OR PUBLIC? CONCEPTUALISING WHAT INTERESTS ARE IMPORTANT}

It is possible to turn to 'patients' or 'the public' to understand what may stabilise or destabilise trust and legitimacy in health research. There is considerable literature and funding opportunities related to involving patients in research projects, and related improved outcomes. ${ }^{6}$ The distinction between public and patients is largely conceptual, but it is important to clarify what aspects of participants' lives we are drawing on to inform research and regulation, and then to structure recruitment and the events to emphasise that focus. ${ }^{7}$ In their role as a patient, or caregivers and advocates for family and friends in healthcare, participants can draw on their experiences to inform clinical care, research and policy. In contrast, decisions that allocate across healthcare needs, or broader public interests, require consideration of a wider range of experiences, as well as the values, and practical knowledge that participants hold as members of the public. Examples of where it is important to achieve a wider 'citizen' perspective include funding decisions on drug expenditures and disinvestment, and balancing privacy concerns against benefits from access to health data or biospecimens. ${ }^{8}$ Considerations of how to involve the public in research priorities is not adequately addressed by involving community representatives on research ethics review committees. ${ }^{9}$

Challenges to trust and legitimacy often arise when there are groups who hold different interpretations of what is in the public interest. Vocal participants on issues are often divide into polarised groups. But there is often also a multiplicity of public interests, so there is no single 'public interest' to be discovered or determined. Each configuration of a balance of interests also has resource implications, and the consequences are borne unevenly across the lines of inequity in society. There is democratic deficit when decisions are made without input from members of public who will be affected by the policy but have not been motivated to engage. This deficit is best addressed by 'actively seek(ing) out moral perspectives that help to identify and explore as many moral dimensions of the problem as possible'. ${ }^{10}$ This rejects the notions that bureaucracies

${ }^{6}$ J. F. Caron-Flinterman et al., 'The Experiential Knowledge of Patients: A New Resource for Biomedical Research?', (2005) Social Science and Medicine, 6o(11), 2575-2584; M. De Wit et al., 'Involving Patient Research Partners has a Significant Impact on Outcomes Research: A Responsive Evaluation of the International OMERACT Conferences', (2013) BMJ Open, 3(5); S. Petit-Zeman et al., 'The James Lind Alliance: Tackling Research Mismatches', (2010) Lancet, 376(9742), 667-669; J. A. Sacristan et al., 'Patient Involvement in Clinical Research: Why, When, and How', (2016) Patient Preference and Adherence, 2016(10), 631-640.

7 C. Mitton et al., 'Health Technology Assessment as Part of a Broader Process for Priority Setting and Resource Allocation', (2019) Applied Health Economics and Health Policy, 17(5), 573-576.

${ }^{8}$ M. Aitken et al., 'Consensus Statement on Public Involvement and Engagement with Data-Intensive Health Research', (2018) International Journal of Population Data Science, 4(1), 1-6; C. Bentley et al., 'Trade-Offs, Fairness, and Funding for Cancer Drugs: Key Findings from a Public Deliberation Event in British Columbia, Canada', (2018) BMC Health Services Research, 18(1), 339-362; S. M. Dry et al., 'Community Recommendations on Biobank Governance: Results from a Deliberative Community Engagement in California’, (2017) PLoS ONE 12(2), 1-14; R. E. McWhirter et al., 'Community Engagement for Big Epidemiology: Deliberative Democracy as a Tool', (2014) Journal of Personalized Medicine, 4(4), 459-474.

9 J. Brett et al., 'Mapping the Impact of Patient and Public Involvement on Health and Social Care Research: A Systematic Review', (2012) Health Expectations, 17(5), 637-650; R. Gooberman-Hill et al., 'Citizens' Juries in Planning Research Priorities: Process, Engagement and Outcome’, (2008) Health Expectations, 11(3), 272-281; S. Oliver et al., 'Public Involvement in Setting a National Research Agenda: A Mixed Methods Evaluation', (2009) Patient, 2(3), 179-190.

10 S. Sherwin, 'Toward Setting an Adequate Ethical Framework for Evaluating Biotechnology Policy', (Canadian Biotechnology Advisory Committee, 2001). As cited in M. M. Burgess and J. Tansey, 'Democratic Deficit and the Politics of "Informed and Inclusive” Consultation' in E. Einsiedel (ed.), From Hindsight to Foresight (Vancouver: UBC Press, 2008), pp. 275-288. 
and elected representatives are adequately informed by experts and stakeholders to determine what is in the interests of all who will be affected by important decisions. These decisions are, in fact, about a collective future, often funded by public funds with opportunity costs. Research regulation, like biotechnology development and policy, must explicitly consider how and who decides the relative importance of benefits and risks.

The distinction between trust and trustworthiness, between bureaucratic legitimacy and perceived social licence, gives rise to the concern that much patient and public engagement may be superficial and even manipulative. ${ }^{11}$ Careful consideration must be given to how the group is convened, informed, facilitated and conclusions or recommendations are formulated. An earlier chapter considered the range of approaches to public and patient engagement, and how different approaches are relevant for different purposes (see Aitkin and CunninghamBurley, Chapter 11). ${ }^{12}$ To successfully stimulate trust and legitimacy, the process of public engagement requires working through these dimensions.

\subsection{CONCEPTUALISING PUBLIC EXPERTISE: REPRESENTATION}

AND INCLUSIVENESS

The use of the term 'public' is normally intended to be as inclusive as possible, but it is also used to distinguish the call to public deliberation from other descriptions of members of society or stakeholders. There is a specific expertise called upon when people participate as members of the public as opposed to patients, caregivers, stakeholders or experts. Participants are sought for their broad life perspective. As perspective bearers coming from a particular structural location in society, with 'experience, history and social knowledge', ${ }^{13}$ participants draw on their own social knowledge and capacity in a deliberative context that supports this articulation without presuming that their experiences are adequate to understand that of others', or that there is necessarily a common value or interest

'Public expertise' is what we all develop as we live in our particular situatedness, and in structured deliberative events it is blended with an understanding of other perspectives, and directed to develop collective advice related to the controversial choices that are the focus of the deliberation. Adopting Althusser's notion of hailing or 'interpellation' as ideological construction of people's role and identity, Berger and De Cleen suggest that calling people to deliberate 'offers people the opportunity to speak (thus empowering them) and a central aspect of how their talk is constrained and given direction (the exercise of power on people)'. ${ }^{14}$ In deliberation, the manifestations of public expertise is interwoven with the overall framing, together co-creating the capacity to consider the issues deliberated from a collective point of view. ${ }^{15}$ Political scientist Mark Warren suggests that '(r)epresentation can be designed to include marginalized people

${ }^{11}$ A. Irwin et al., 'The Good, the Bad and the Perfect: Criticizing Engagement Practice', (2013) Social Studies of Science, 43(1), 118-135; S. Jasanoff, The Ethics of Invention: Technology and the Human Future (Manhattan, NY: Norton Publishers, 2016); B. Wynne, 'Public Engagement as a Means of Restoring Public Trust in Science: Hitting the Notes, but Missing the Music?', (2006) Community Genetics 9(3), 211-220.

${ }^{12}$ J. Gastil and P. Levine, The Deliberative Democracy Handbook: Strategies for Effective Civic Engagement in the Twenty-First Century (Plano, TX: Jossey-Bass Publishing, 2005).

${ }^{13}$ I. M. Young, Inclusion and Democracy (Oxford University Press, 2000), p. 136.

${ }^{14}$ M. Berger and B. De Cleen, 'Interpellated Citizens: Suggested Subject Positions in a Deliberation Process on Health Care Reimbursement', (2018) Comunicazioni Sociali, 1, 91-103; L. Althusser, 'Ideology and Ideological State Apparatuses: Notes Towards an Investigation' in L. Althusser (ed.) Lenin and Philosophy and Other Essays (Monthly Review Press, 1971), pp. 173-174.

${ }^{15}$ H. L. Walmsley, 'Mad Scientists Bend the Frame of Biobank Governance in British Columbia', (2009) Journal of Public Deliberation, 5(1), Article 6. 
and unorganized interests, as well as latent public interests. ${ }^{16}$ As one form of deliberation, citizen juries, captured in the name and process, the courts have long drawn on public to constitute a group of peers who must make sense and form collective judgments out of conflicting and diverse information and alternative normative weightings. ${ }^{17}$

Simone Chambers, in a classic review of deliberative democracy, emphasised two critiques from diversity theory, and suggested that these would be a central concern in the next generation of deliberative theorists: (1) reasonableness and reason-giving; (2) conditions of equality as participants in deliberative activities. ${ }^{18}$ The facilitation of deliberative events is discussed below, but participants can be encouraged and given the opportunity to understand each other's perspectives in a manner that may be less restrictive than theoretical discussions suggest. For example, the use of narrative accounts to explain how participants come to hold particular beliefs or positions provide important perspectives that might not be volunteered or considered if there was a strong emphasis on justifying one's views with reasons in order for them to be considered. ${ }^{19}$

The definition and operationalisation of inclusiveness is important because deliberative processes are rarely large scale, focussing instead on the way that small groups can demonstrate how a wider public would respond if they were informed and civic-minded. ${ }^{20}$ Representation or inclusiveness is often the starting place for consideration of an engagement process. ${ }^{21}$ Steel and colleagues have described three different types of inclusiveness that provides conceptual clarity about the constitution of a group for engagement: representative, egalitarian and normic diversity. ${ }^{22}$

Representative diversity requires that the distribution of the relevant sub-groups in the sample reflects the same distribution as in the reference population. Egalitarian inclusiveness requires equal representation of people from each relevant sub-group so that each perspective is given equal representation. In contrast to representative diversity, Egalitarian diversity ignores the size of each sub-group in the population, and emphasises equal representation of each sub-group. Normic diversity requires the over-representation of sub-groups who are marginalised or overwhelmed by the larger, more influential or mainstream groups in the population. Each of these concepts aim for a symmetry, but the representative approach presumes that symmetry is the replication of the population, while egalitarian and normic concepts directly consider asymmetry of power and voice in society.

Attempts to enhance the range of perspectives considered in determining the public interest(s) is likely to draw on the normic and egalitarian concepts of diversity, and de-emphasise the representative notion. The goal of deliberative public engagement is to address a democratic deficit whereby some groups have been the dominant perspectives considered on the issues, even if none have prevailed over others. It seeks to include a wider range of input from diverse citizens about how to live together given the different perspectives on what is in the public

16 M. E. Warren, 'Governance-Driven Democratization', (2009) Critical Policy Studies, 3(1), 3-13, 10.

17 G. Smith and C. Wales, 'Citizens' Juries and Deliberative Democracy', (2000) Political Studies, 48(1), 51-65.

18 S. Chambers, 'Deliberative Democratic Theory', (2003) Annual Review of Political Science, 6, 307-326.

19 M. M. Burgess et al., 'Assessing Deliberative Design of Public Input on Biobanks' in S. Dodds and R. A. Ankeny (eds) Big Picture Bioethics: Developing Democratic Policy in Contested Domains (Switzerland: Springer, 2016), pp. $243-276$.

${ }^{2 \circ}$ R. E. Goodin and J. S. Dryzek, 'Deliberative Impacts: The Macro-Political Uptake of Mini-Publics', (2006) Politics \& Society, 34(2), 219-244.

${ }^{21}$ H. Longstaff and M. M. Burgess, 'Recruiting for Representation in Public Deliberation on the Ethics of Biobanks', (2010) Public Understanding of Science, 19(2), 212-24.

${ }_{22}$ D. Steel et al., 'Multiple Diversity Concepts and Their Ethical-Epistemic Implications', (2018) The British Journal for the Philosophy of Science, 8(3), 761-780. 
interest. Normic diversity suggests that dominant groups are less present in the deliberating group, and egalitarian suggests that it is important to have similar representation across the anticipated diverse perspectives. The deliberation must be informed about, but not subjugated by, dominant perspectives, and one approach is to exclude dominant perspectives, including those of substance experts, from participating in the deliberation, but introduce their perspectives and related information through materials and presentations intended to inform participants. Deliberative participants must exercise their judgement and critically consider a wide range of perspectives, while stakeholders are agents for a collective identity that asserts the importance of one perspective over others. ${ }^{23}$ It is also challenging to identify the range of relevant perspectives that give particular form to the public expertise for an issue, although demographics may be used to ensure that participants reflect a range of life experiences. ${ }^{24}$ Specific questions may also suggest that particular public perspectives are important to include in the deliberating group. For example, in Californian deliberations on biobanks it was important to include Spanish-only speakers because, despite accounting for the majority of births, they were often excluded from research regulation issues (normic diversity), and they were an identifiable group who likely had unique perspectives compared to other demographic segments of the California population (egalitarian diversity). ${ }^{25}$

\subsection{MOBILISING PUBLIC EXPERTISE IN DELIBERATION}

As previously discussed, mobilising public expertise requires considerable support. To be credible and legitimate, a deliberative process must demonstrate that the participants are adequately informed and consider diverse perspectives. Participants must respectfully engage each other in the development of recommendations that focus on reasoned inclusiveness but fully engage the trade-offs required in policy decisions.

It seems obvious that participation in an engagement to advise research regulation must be informed about the activities to be regulated. This is far from a simple task. An engagement can easily be undermined if the information provided is incomplete or biased. It is important to provide not only complete technical details, but also ensure that social controversies and stakeholder perspectives are fairly represented. This can be managed by having an advisory of experts, stakeholders and potential knowledge users. Advisors can provide input into the questions and the range of relevant information that participants must consider to be adequately informed. It is also important to consider how best to provide information to support comprehension across participants with different backgrounds. One approach is to utilise a combination of a background booklet and a panel of four to six speakers. ${ }^{26}$ The speakers, a combination of experts and stakeholders, are asked to be impassioned, explaining how or why they come to their particular view. This will establish that there are controversies, help draw participants into the issues and stimulate interest in the textual information.

Facilitation is another critical element of deliberative engagement. Deliberative engagement is distinguished by collective decisions supported by reasons from the participants - the recommendations and conclusions are the result of a consideration of the diverse perspectives reflected in the process and among participants. The approach to facilitation openly accepts that

${ }^{23}$ K. Beier et al., 'Understanding Collective Agency in Bioethics', (2016) Medicine, Health Care and Philosophy, 19(3), $411-422$.

${ }^{24}$ Longstaff and Burgess, 'Recruiting for Representation'.

${ }^{25}$ S. M. Dry et al., 'Community Recommendations on Biobank Governance'.

${ }^{26}$ Burgess et al., 'Assessing Deliberative Design', pp. 270-271. 
participants may re-orient the discussion and focus, and that the role of facilitation is to frame the discussion in a transparent manner. ${ }^{27}$ Small groups of six to eight participants can be facilitated to develop fuller participation and articulation of different perspectives and interests than is possible in a larger group. Large group facilitation can be oriented to giving the participants as much control over topic and approach as they assume, while supporting exploration of issues and suggesting statements where the group may be converging. The facilitator may also draw closure to enable participants to move on to other issues by suggesting that there is a disagreement that can be captured. Identifying places of deep social disagreement identifies where setting policy will need to resolve controversy about what is genuinely in the public's interest, and where there may be a need for more nuanced decisions on a case-by-case basis. The involvement of industry and commercialisation in biobanks is a general area that has frequently defied convergence in deliberation. ${ }^{28}$

Even if recruitment succeeds in convening a diverse group of participants, sustaining diversity and participation across participants requires careful facilitation. The deliberative nature of the activity is dynamic. Participants increase their level of knowledge and understanding of diverse perspectives as facilitation encourages them to shift from an individual to a collective focus. Premature insistence on justifications can stifle understanding of diverse perspectives, but later in the event, justifications are crucial to produce reasons in support of conclusions. Discussion and conclusions can be inappropriately influenced by participants' personalities, as well as the tendency for some participants to position themselves as having authoritative expertise. It is well within the expertise of the public to consider whether claims to special knowledge or personalities are lacking substantive support for their positions. But self-reflective and respectful communication is not naturally occurring, and deliberation requires skilled facilitation to avoid dominance of some participants and to encourage critical reflection and participation of quieter participants. The framing of the issues and information as well as facilitation inevitably shapes the conclusions, and participants may not recognise that issues and concerns important to them have been ruled out of scope.

Assessing the quality of deliberative public engagement is fraught with challenges. Abelson and Nabatchi have provided good overviews of the state of deliberative civic engagement, assessing its impacts and assessment. ${ }^{29}$

There are recent considerations of whether and under what conditions deliberative public engagement is useful and effective. ${ }^{30}$ Because deliberative engagement is expensive and resource intensive, it needs to be directed to controversies where the regulatory bodies want, and are willing, to have their decisions and policies shaped by public input. Such authorities do not thereby give up their legitimate duties and freedom to act in the public interest or to consult with experts and stakeholders. Rather, activities such as deliberative public engagement are

${ }^{27}$ A. Kadlec and W. Friedman, 'Beyond Debate: Impacts of Deliberative Issue Framing on Group Dialogue and Problem Solving', (Center for Advances in Public Engagement, 2009); H. L. Walmsley, 'Mad Scientists Bend the Frame of Biobank Governance in British Columbia', (2009) Journal of Public Deliberation, 5(1), Article 6.

${ }_{28}$ M. M. Burgess, 'Deriving Policy and Governance from Deliberative Events and Mini-Publics' in M. Howlett and D. Laycock (eds), Regulating Next Generation Agri-Food Biotechnologies: Lessons from European, North American and Asian Experiences (Abingdon: Routledge, 2012), pp. 220-236; D. Nicol, et al., 'Understanding Public Reactions to Commercialization of Biobanks and Use of Biobank Resources', (2016) Social Sciences and Medicine, 162, 79-87.

${ }^{29}$ J. Abelson et al., 'Bringing 'The Public' into Health Technology Assessment and Coverage Policy Decisions: From Principles to Practice', (2007) Health Policy, 82(1), 37-50; T. Nabatchi et al., Democracy in Motion: Evaluating the Practice and Impact of Deliberative Civic Engagement (Oxford University Press, 2012).

$3^{\circ}$ D. Caluwaeerts and M. Reuchamps, The Legitimacy of Citizen-led Deliberative Democracy: The Grooo in Belgium (Abingdon: Routledge, 2018). 
supplemental to the other sources of advice, and not determinative of the outcomes. This point is important for knowledge users, sponsors and participants to understand.

How, then, might deliberative public engagement have helped avoid the negative reaction to care.data? It is first important to distinguish trust from trustworthiness. Trust, sometimes considered as social licence, is usually presumed in the first instance. As a psychological phenomenon, trust is often a heuristic form of reasoning that supports economical use of intellectual and social capital. ${ }^{31}$ There is some evidence that trust is particularly important with regard to research participation. ${ }^{32}$ Based on previous experiences, we develop trust - or distrust - in people and institutions. There is a good chance that many people whose records are in the NHS would approach the use of their records for other purposes with a general sense of trust. Loss of trust often flows from abrupt discovery that things are not as we presumed, which is what appears to have happened in care.data. On the other hand, trustworthiness of governance is when the governance system has the characteristics that, if scrutinised, would support that it is worthy of trust.

Given this understanding, it might have been possible to demonstrate trustworthiness of governance of the NHS data by holding deliberative public engagement and considering its recommendations for data management. Also, public trust might not have been as widely undermined if the announcement of extension of access to include commercial partners provided a basis for finding the governance trustworthy. Of course, distrust of critical stakeholders and members of public will still require direct responses to their concerns.

It is important to note that trustworthiness that can stand up to scrutiny is the goal, rather than directing efforts at increasing trust. Since trust is given in many cases without reflection, it can often be manipulated. By aiming at trustworthiness, arrived at through considerations that include deliberative public input, the authorities demonstrate that their approach is trustworthy. Articulating how controversies have been considered with input from informed and deliberating members of public would have demonstrated that the trust presumed at the outset was, in an important sense, justified. Now, after the trust has been lost and education and reinforced individual consent has not addressed the concerns, deliberation to achieve legitimate and trustworthy governance may have a more difficult time stimulating wide public trust, but it may remain the best available option.

\subsection{CONCLUSION}

Deliberative public engagement has an important role in the regulation of health research. Determining what trade-offs are in the public interest requires a weighing of alternatives and relative weights of different interests. Experts and stakeholders are legitimate advocates for the interests they represent, but their interests manifest an asymmetry of power. Including a welldesigned process to include diverse public input can increase the legitimacy and trustworthiness of the policies. Deliberative engagement mobilises a wider public to direct their collective experience and expertise. The resulting advice about what is in the public interest explicitly builds diversity in the recruitment of the participants and in the design of the deliberation.

${ }^{31}$ G. Gigerenzer and P. M. Todd, 'Ecological Rationality: The Normative Study of Heuristics', in P. M. Todd and G. Gigerenzer (eds), Ecological Rationality: Intelligence in the World (Oxford University Press, 2012).

${ }^{2}$ E. Christofides et al., 'Heuristic Decision-Making About Research Participation in Children with Cystic Fibrosis', (2016) Social Science \& Medicine, 162, 32-40; O’Doherty and Burgess, 'Developing Psychologically Compelling Understanding'; M. M. Burgess and K. C. O’Doherty, 'Moving from Understanding of Consent Conditions to Heuristics of Trust', (2019) American Journal of Bioethics, 19(5), 24-26. 
Deliberative public engagement is helpful for issues where there is genuine controversy about what is in the public interest, but it is far from a panacea. It is an important complement to stakeholder and expert input. The deliberative approach starts with careful consideration of the issues to be deliberated and how the diversity is to be structured into the recruitment of a deliberating small group. Expert and stakeholder advisors, as well as decision-makers who are the likely recipients of the conclusions of the deliberation, can help develop the range of information necessary for deliberation on the issues to be informed. Participants need to be supported by exercises and facilitation that helps them develop a well-informed and respectful understanding of diverse perspectives. Facilitation then shifts to support the development of a collective focus and conclusions with justifications. Diversity and asymmetry of power is respected through the conceptualisation and implementation of inclusiveness, the development of information, and through facilitation and respect for different kinds of warranting. There must be a recognition that the role of event structure and facilitation means that the knowledge is co-produced with the participants, and that it is very challenging to overcome asymmetries, even in the deliberation itself. Another important feature is the ability to identify persistent disagreements and not force premature consensus on what is in the public interest. In this quality, it mirrors the need for, and nature of, regulation of health research to struggle with the issue of when research is in 'the public interest'.

It is inadequate to assert or assume that research and its existing and emerging regulation is in the public interest. It is vital to ensure wide, inclusive consideration that is not overwhelmed by economic or other strongly vested interests. This is best accomplished by developing, assessing and refining ways to better include diverse citizens in the informed reflections about what is in our collective interests, and how to best live together when those interests appear incommensurable. 